Article

\title{
Organizing the Co-Production of Health and Environmental Values in Food Production: The Constitutional Processes in the Relationships between Italian Solidarity Purchasing Groups and Farmers
}

\author{
Gaetano Martino ${ }^{1}$, Giulia Giacchè ${ }^{2}$ and Enrica Rossetti ${ }^{1, *}$ \\ 1 Department of Agricultural, Food and Environmental Sciences, University of Perugia, Borgo XX giugno, 74, \\ Perugia 06124, Italy; gaetano.martino@unipg.it \\ 2 European University of Brittany, University of Rennes2 - 5 Boulevard Laënnec 35000 Rennes France; \\ ggiulia@hotmail.com \\ * Correspondence: e.rossetti@hotmail.it; Tel.: +39-075-5857-135
}

Academic Editor: Marc A. Rosen

Received: 29 November 2015; Accepted: 24 March 2016; Published: 30 March 2016

\begin{abstract}
The paper focuses on the Solidarity Purchasing Group (SPG), defined as a group of households that establishes an organization primarily to provide food to its members. The study aims at illustrating and testing two hypotheses. The first is that within the group, specific organizational processes take place according to which food communication practices determine the resource use objectives. The second hypothesis is the SPG tends to assign larger values to health and environmental protection than other resource use objectives. These hypotheses concern the ranking of the resource use objectives managed by the group. The idea is that an SPG defines the resource uses according to the specific group's objectives and by means of organizational tools, especially the food communication practices. For testing purposes, we conducted an empirical analysis by submitting an online questionnaire to 900 Italian SPGs. The results firstly indicate that the organizational dimensions of SPGs, including the relationships between SPGs and farmers, influence the group objectives, providing empirical evidence that supports the first hypothesis. Moreover, the test of the second hypothesis indicates that group objectives concerning health and environmental protection are particularly valued by the SPGs. We then conclude that the groups are aimed at co-producing health and environmental protection with public authorities. We then underlined limits of the study and potential future research paths.
\end{abstract}

Keywords: solidarity purchasing groups; organization; constitutional process; co-production

\section{Introduction}

A Solidarity Purchasing Group (SPG) is a group of households set up to provide food to its members [1]. SPGs invest resources in selecting food producers and often engage consumers in designing and managing products and production processes as another type of food network in contemporary food systems [2-4]. As another type of food network [5], the SPGs are required to investigate the organizational dimensions of the product-consumption relationships. We examine the group organization by focusing on how decision rights are allocated between producers and consumers and, especially, by focusing on the rankings relating to the impact the use of resources has on the goods provisioned by the group. Namely, the objective of this study was to test two hypotheses. The first hypothesis is that communication practices determine the groups' resource use objectives. 
The second is that the groups tend to assign larger values to health and environmental protection than other resource use objectives.

The SPG's organizational structure has only been partially considered in the literature $[1,5,6]$, whereas taking into account group organization contributes to a more comprehensive understanding of how the group could achieve its goals. In the first level of analysis, we argue that an organization plays a role in allowing for the management of goods provision of a different economic nature and the achievement of the multiple use values of the food (functional, hedonic, aesthetic, symbolic, ethical) [1,7]. In the light of the theory of organization, this study analyzed SPG organizations by taking into account resource use objectives as a step in the development of organizational constitutional processes [8]. We define a constitutional process as a sequence of actions undertaken and decisions made which are aimed at establishing an organization. Key constitutional steps are the pooling of resources owned by the parties, the distribution of decision-making rights and the ranking of the parties assigned to the resource uses [8].

The second level of analysis concerns the processes entailed by the SPG's activities. The literature on SPGs converges on focusing on the purchasing activity and the co-production of food by the SPG and farmers $[9,10]$. We identify a further type of co-production that entails the joint activity of the SPG and public authorities in order to produce health statuses and environment protection. When private citizens control some inputs needed to produce an output relevant to society, the public and private sector can co-produce that output if the inputs they control are complementary [11,12]. At a social level, health outcomes and environmental protection are achieved through inputs that are under the control of both the private and public sectors. Focusing on SPGs, we point out that farmers manage natural, social, human and physical capital assets and are expected to allocate them sustainably [13]. Furthermore, the available sustainable technologies must be adopted locally and adapted to the place by the tacit knowledge of farmers [13]. Consumers can use their knowledge about food characteristics to direct diets in a healthy direction. Public authorities develop and implement interventions in the fields of human health and environmental protection. In many countries-including Italy, where we carried out the empirical analysis—regional and national agencies and governments provide health services and regulate the private supply of medical assistance. Analogously, public agencies intervene in the field of environmental protection by setting constraints and sanctions, managing natural areas, implementing educational programs, and so forth. SPGs, then, act at the group and individual levels, and public agencies act at higher levels: regional, national or supranational. This difference in operational scale does not impede the SPG's promotion of sustainable food consumption and production, favoring health and environmental protection as, at a different scale, the public sector does. It has to be pointed out that while the expected health outcomes concern only the SPG members (as consumers of healthy food), the expected environmental protection outcomes regard the territory in which the SPG operates.

This study is organized as follows. First, we present the conceptual framework. The theory of organization allows us to investigate how, through constitutional processes [8], the SPGs align the ranking of their and farmers' resources with the objectives of the group. The concept of food practices [14] permits detailed investigation of the constitutional processes in the view of organization theory [15]. For testing purposes, we conducted an empirical analysis by submitting an online questionnaire to 900 Italian SPGs. The results indicate that SPGs engage themselves in the provision of food but also concentrate on specific dimensions of food. Health and environmental protection are valued as the main objective of SPGs. In the final remarks, we emphasise some limits of our study and recommend directions for future research. 


\section{Conceptual Framework}

\subsection{Allocation of Decision Rights}

We establish an analytical relation between relevant organizational features of the SPG (the allocation of the decision rights and the ranking of the resource use objectives) and the co-production of health and environmental values. Figure 1 summarizes the causal nexus we identify in the conceptual framework of the study. Subsequently, we define the study's conceptual framework on the basis of these relationships. At the very core of the SPG, there is no consumer choice but there is group activity, and this makes the organizational characteristics strategically relevant.

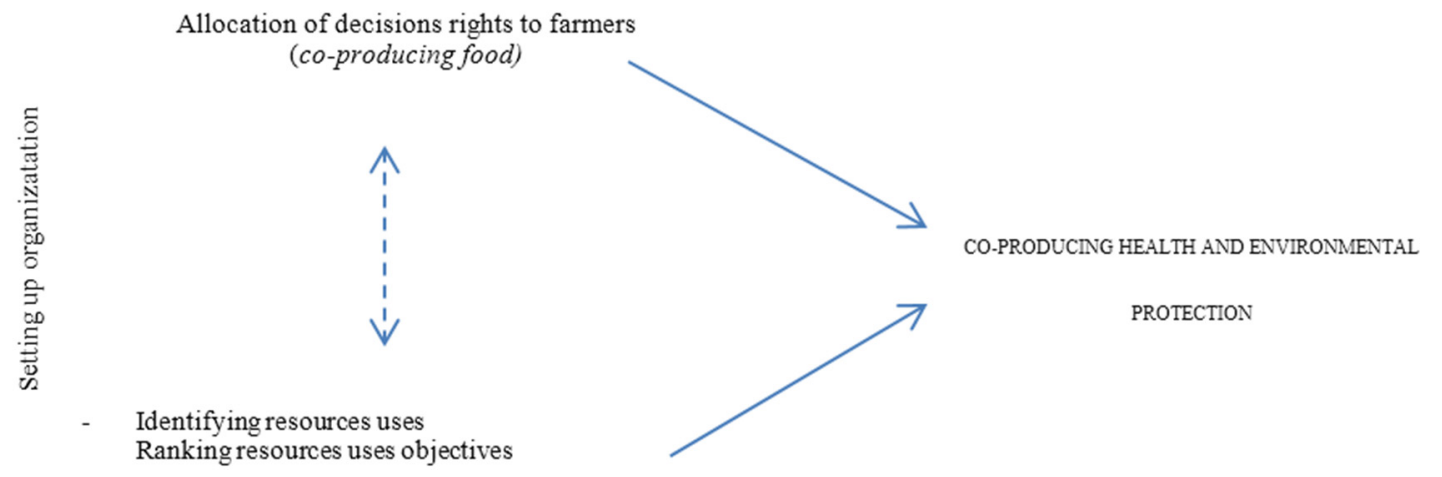

Figure 1. Organization setting and co-production.

Pascucci [1] views SPGs as an example of food community networks, i.e., as governance structures where consumers and producers strongly integrate their functions (goals) through a "community networking mechanism", based on sharing and pooling resources which are specific to the two parties, and also based on using membership to assign decision-making and/or property rights.

Like many other food networks, SPGs generate a connection between production and consumption, but a comparison with other forms sheds light on the SPGs' specific features:

(a) Although the SPG establishes a direct contact with producers (mainly farmers), as in the case of Community-Supported Agriculture [16], it differs from this for three main reasons: firstly, SPGs do not systematically share the production risk with the farmer, given that no payment is made for the product at the start of the production process; secondly, SPGs do not apply systematic budgeting to the production process; thirdly, SPGs tend to emphasize the link between consumption and citizenship [1,17], rather than gaining benefits from supporting producers, accessing the land and contributing to the establishment of a local food system;

(b) SPGs operate mainly on a local economic scale [1], but even if they are primarily based on face-to-face interaction, as in the case of box schemes, farmers markets or farm shops [3], SPGs are increasingly expanding the system of relationships towards a proximity pattern that, by mail and telephone contacts, enlarges the area for producer-consumer contacts.

From an organizational point of view, co-production between an SPG and farmers $[9,10]$ has to be conceptualized in terms of the allocation of decision rights from the agricultural producers to the SPG [8]. As a network, the SPG is characterized by the way the decision rights are allocated among the members [18]: in an SPG the farmers allocate to the consumers the right to decide some way to carry out a production task or to decide the time of delivering products (right to decide the use of the farm's resources). On the farmer's side, the rationale for the allocation of critical decision rights to the SPG is grounded in the gains arising from the exchange relationship. The stability of delivering agricultural products to the SPG allows farmers to cope with market uncertainty. To cope with uncertainty is the main motivation for the allocation of decision rights to an organizational 
partner $[8,18]$. Correspondingly, on the SPG's side, the allocation of decision rights from a farmer allows the group to manage certain critical productive tasks related to qualitative characteristics of a product that is relevant to the SPG. This possibility allows the SPG to cope with technological uncertainty. Although analyzing the negotiation process is beyond the scope of our empirical analysis and of the conceptual framework adopted, it is important to affirm that the allocation of decision rights is not a unilateral decision. In fact, even though negotiation between an SPG and the farmers is very simply undertaken, it cannot be taken for granted that a farmer agrees to adopt the production techniques preferred by the SPG. Of course, the selection of farmers reduces the difficulties related to negotiation.

\subsection{Ranking the Resources Uses}

The second detailed aspect of SPGs organization considered here is the identification of the group's objectives in terms of food characteristics. The consequential ranking of the resource uses is an antecedent of the allocation of decision rights and grounds the organization of the SPG [8].

An SPG owns and manages several resources. The group is endowed with codified and tacit knowledge about production and consumption technologies. The group itself is also engaged in knowledge creation [7]. Furthermore, it establishes relationships with other public and private entities, including the national-level SPGs network. The group also manages a small amount of financial resources gathered at the member level. Sometimes local public authorities grant the resources to support logistical activities. The producers own both material and immaterial resources: land, equipment, financial capital, labor and knowledge. We propose an operational definition of resource use objective as the intended goal at which a given resource use is aimed in the context of an SPG's activities. The goal may be aimed at the quantity or quality—or both—of the product. However, it may also concern the production of positive externalities and the reduction of negative externalities.

The parties of an organization pool their resources to the specific organizational ends $[8,18]$. Therefore, they have to design or identify the complementarity among the resource uses and rank the resources with respect to these potential uses [8]. The ranking of the resource use objectives guides the resources ranking and is a critical step in the organizational setting.

Resource ranking is not the result of simple unique decisions made by the group but, rather, it emerges as the outcome of organizational practices [15] that implement the production-consumption relationship. The intended uses of resources thus characterize the resource-pooling. Food consumption embraces a complex set of practices $[14,19,20]$. Grey et al. [21] connected the framing-as a process making salient aspects of reality in such a way as to promote a particular problem definition, causal interpretation, moral evaluation, and/or treatment recommendation [22] — to a process of establishing higher institutional levels from micro-interactions. Applying this view to an SPG highlights the role of communication practices as means supporting the interaction among the SPG members and the group's stability $[7,20,23]$. The SPG communication practices make the group resource rankings able to construct a system of activities aimed at achieving the resource uses fitting the group objectives. For example, purchasing local food requires the group to invest resources in seeking local producers; providing safe food requires selecting products from producers or directing the production process with the farmers. Although the nexus between the group objectives and resource uses may not be unique - as many technologies may be available—the ranking of the group objectives necessarily entails ranking the resource uses. There are three reasons that support this causal sequence, from communication to group objectives. Firstly, the structuring capability of the practice [23] allows the setting of the organization as stable system of activities. Secondly, the communication practices connect the practical understanding to the SPG motivational base [24]. The third reason is that the communication causes the emerging of a common—or at least convergent-cognitive frame of the group members [7] which makes the micro-interactions among the members stable [21]. The group thus becomes able to specify the resource use objectives. Based on the conceptual framework proposed, we hypothesized that in the action situation, the communication practices and the action situation 
variables have a statistically significant effect on the values that the group assigns to the resource use objectives (hypothesis $H_{1}$ ).

\subsection{Co-Producing Health and Environmental Values}

In the SPGs, the focus of actors is not on the characteristics of food per se, but rather on the multiple use values of the food.

Elaborating on [25], we posit that through food provision, the SPG pursues health and environmental objectives. Food networks, like SPGs, stress the relationship between food and health, seeking to achieve it by fostering direct contact between consumers and producers [26]. The health and environmental objectives in food networks are connected to the values within the consumer-producer relationships and may improve the embeddedness and the transparency of food networks $[3,27]$.

In sum, we hypothesize that the values that the group assigns to the resource use objectives are larger for health and environmental objectives than for the remaining uses (hypothesis $\mathrm{H}_{2}$ ). This implies that the SPG finalizes its organization to co-produce health and environmental protection. However, a group may not succeed in co-producing health and environmental protection for several reasons, including the size of the transaction costs the consumers should bear in dealing with the farmers [1]. It is out of the scope of this study to verify whether or not a finalized SGP organization really allows a group to succeed. As illustrated in Figure 1, hypotheses $H_{1}$ and $H_{2}$ are then connected in terms of the processes constituting the organization in which the use values are channeled to specify the resource rankings with respect to the resource objectives.

\section{Empirical Analysis}

\subsection{Methods of the Empirical Analysis}

To test the two hypotheses, we adopted a quantitative approach. The provisioning of products to group members is managed at the group level and, consequently, the objectives linked to resource uses and the types of products to be purchased are decided at this collective level. Therefore, the unit of analysis of this study is the solidarity purchasing group.

The population considered in this study includes all the SPGs active in Italy in 2013. The number of these groups was not certain. According to Grasseni et al. [28], the total number was approximately 1500 and the national network of the SPGs-Retegas-included 920 groups, distributed mainly in northern and central Italy. We therefore chose Retegas as our convenience sample [29]. Retegas pursues a number of goals in the field of supportive economy: o promote purchasing at small farms; to highlight product choice criteria; to promote the exchange of information about products and producers. However, the ties between Retegas and single SPGs are weak: although Retegas provides general information on how to set up a group and aims at promoting a general common view, each group acts autonomously, managing its own decision rights.

We submitted an online questionnaire to 900 Italian SPGs contacted through the active e-mail addresses that were available through the Italian SPGs network ReteGas The questionnaire included two blocks of questions: (i) questions about the general characteristics of each SPG (i.e., year of foundation, number of members, field of activity); and (ii) questions about the SPG action situation positions (i.e., president/coordinator, management, assembly, and product manager).

Drawing from [1,7] we proposed to the respondent three sets of resource use objectives:

(1) Health

- $\quad$ To select farmers able to supply safe food, i.e., food not contaminated with potentially harmful bacteria, parasites, viruses, toxins and chemicals (SAFETY)

- $\quad$ To define the production process, to receive the decision rights from the farmers about the food production process (DIRECTING)

- $\quad$ To select food with "no residuals" (NORESIDUALS) 
- To select food with "no preservatives" (NOCONSERV)

- To select foods for children (KID_FOODS)

(2) Environment

- To select farmers on a geographic basis (ZONE OF PRODUCTION)

- To choose food grown nearby (CLOSENESS)

- To choose food with reduced environmental impacts (ENVIRONMENTAL IMPACT)

- To enhance transportation logistics (LOGISTIC)

- To select products from traditional genetic strains, i.e., products from crops or animals that are part of the cultural tradition of a territory (TRADITIONAL GENOTYPES)

(3) Convenience, Ethical, Symbolic and Hedonic Use Values

- To choose low-priced food (LOWPRICE)

- To choose foods produced according to ethical guidelines (ETHIC)

- To choose traditional foods (TRADITIONAL FOODS)

- To choose foods with a given degree of preparation, e.g., bread, juices, marmalades (ELABORATED FOODS)

- To choose continuously available food (AVAILABILITY)

The respondents were then required to assign a score to each objective by answering the following question: How do you evaluate the following objectives in the context of your group's strategy? We used a seven-point Likert scale $(-3=$ no relevance $;-2=$ very low relevance; $-1=$ low relevance; $0=$ undecided; $1=$ enough relevant; 2 = relevant; and 3 = high relevance). The idea was that, because of their position, the respondents would be able to express an average evaluation of the group objectives and the resource use objectives.

The first two sets related to health and environmental objectives, respectively, and corresponded to the main functional characteristics of the SPG [7]. SAFETY was intended as the level of health safety; NORESIDUALS relates to the zero level of pesticides; NOCONSERV is the absence of preservatives. DIRECTING captures the group's intention to manage the production process jointly with producers; we included it in the healthy set, as it is usually aimed at health objectives [7]. This resource use objective directly accounts for the allocation of decision rights from the farmers to the SPG. In fact, the goal to direct the production process corresponds to management in which the decisions over the farms' resources are at least partially made by the SPG. Furthermore, the purchase of food for children is aimed at acquiring healthy food; thus, we included KID_FOODS in the first set of objectives. The objectives related to the environment were generally designed to capture the capability of the respondent to address environmental concerns in an operational context. Thus, the ZONE OF PRODUCTION indicates the perceived quality of the production environment, whereas its proximity (CLOSENESS) and logistical enhancements (LOGISTIC) were related to the impacts of transportation. ENVIRONMENTAL IMPACT captures the general perception of the respondents, and TRADITIONAL GENOTYPE reflects the perception of the impact from the diffusion of artificial genetic varieties.

We then considered various objectives under the general label of the third group of SPG objectives. The first reason for such a choice was that the economic and ethical concerns were not a systematic objective, and cultural aspects are not easily disentangled from others [25]. The second reason was analytical: the objectives cannot be classified as functional, but they are either ethical (ETHIC), symbolic (TRADITIONAL FOOD, ELABORATED FOOD), hedonic (AVAILABILITY) or simply economic (LOWPRICE) in nature [7].

In submitting the questionnaire, we did not present the objectives to be evaluated grouped in the three sets to avoid anchoring [30]. We simply presented the respondents with a list of objectives and grouped them into three sets in the data analysis stage. 
For the purpose of the empirical analysis, we frame the SPG network in terms of action situation [31]. Ostrom [31] states that when two or more individuals are faced with a set of potential actions that jointly produce outcomes, these individuals are in an "action situation". The structure of an action situation includes a set of participants, positions to be filled by the participants, potential outcomes, a set of allowable actions, functions that map action into realized outcomes, control that an individual has over these functions, information available to participants about an outcome and their relationships, and costs and benefits associated with actions and outcomes [31]. Therefore, we considered each SPG engaged in an action situation [31] and we identified the structure of the SPG action situations with a literature analysis. The Participants of the group are citizens, farmers, and other producers as well as other SPGs that may be in contact with the group and could contribute to information-gathering about products, processes or strategic decisions [3]. The Positions in the group usually include the following: (a) the members of the SPG assembly are citizens who decided to join the group; (b) the product manager is responsible for collecting purchasing orders from the members, channeling the orders towards the farmers and contributing to the distribution logistics [7]; (c) the president that officially represents the group and normally leads with board assistance and under the assembly's direction [7]; and (d) the board members that provide the decision-making balance between the assembly and the board based on the history of the group and prominent values of the members $[7,25]$.

We operationalized the concept of food communication practices by jointly considering the means of communication (direct contact, mail, phone) and the actor of the communication. We distinguished the types of communication practices by taking into account the evidence in the literature, pointing out the importance of the assembly and e-mail communication [7]. We also considered phone communication for the sake of completeness. We did not formulate any opinions about the potentially different roles of the three means of communication considered: firstly, because there is no systematic evidence about communication practices; secondly, because it is beyond the scope of the hypothesis to explain the potential differences among the influences of the different means of communication. Accordingly, we did not gather any information about the content of the communication. This does not mean that we considered the analysis of the different influences to be insignificant (rather, we expected differences), but it simply corresponds to the study objective as a first step of inquiry in this new field.

As for the Positions variables, the literature offers an unsystematic understanding, but confirms that one should expect that different subjects—having a different position-present a diverse capability to influence the resource use objectives $[3,7,25]$. Beyond the members of the group (also including the product managers) and the president/coordinator, we also considered subjects external to the group. The group was actually in touch with farmers for the purpose of directing production activity [10]; additionally, they were in touch with public authorities and with the national-level SPG network for governance reasons [7,25], and to promote governance and policy, respectively [7,25]. We also considered the type of provision (food, culture, clothes) as control variables. The control variables allow us to take into account the potential effects on the dependent variables caused by the variety of the SPGs activities rather than by action situation variables and communication practices. Communication practices, positions and control variables were specified as dummies with 0,1 values; these variables are listed in Table 1. 
Table 1. List of the exogenous variables in Generalized Linear Model models.

\begin{tabular}{|c|c|c|c|}
\hline Type of Variables & Variables & Symbol & Codes \\
\hline \multirow{4}{*}{ Positions } & President & Pres & 0,1 \\
\hline & Management & Manag & 0,1 \\
\hline & Assembly of the members & Assembly & 0,1 \\
\hline & Product manager & Prodman & 0,1 \\
\hline \multirow{3}{*}{ Types of provision } & Provision of food & Food & 0,1 \\
\hline & Provision of clothing & Dress & 0,1 \\
\hline & Provision of culture & Culture & 0,1 \\
\hline \multicolumn{4}{|c|}{ Members } \\
\hline \multirow{19}{*}{$\begin{array}{l}\text { Communicative } \\
\text { practices }\end{array}$} & Direct contact & Membcont & 0,1 \\
\hline & Phone & Membph & 0,1 \\
\hline & Mail & Membra & 0,1 \\
\hline & \multicolumn{3}{|c|}{ President } \\
\hline & Direct contact & Prescont & 0,1 \\
\hline & Phone & Presph & 0,1 \\
\hline & Mail & Presma & 0,1 \\
\hline & \multicolumn{3}{|c|}{ Farmer } \\
\hline & Direct contact & Farmacont & 0,1 \\
\hline & Phone & Farmph & 0,1 \\
\hline & Mail & Farmma & 0,1 \\
\hline & \multicolumn{3}{|c|}{ Public Authorities } \\
\hline & Direct contact & Authcont & 0,1 \\
\hline & Phone & Authph & 0,1 \\
\hline & Mail & Automa & 0,1 \\
\hline & \multicolumn{3}{|c|}{ SPGs Network } \\
\hline & Direct contact & Netcont & 0,1 \\
\hline & Phone & Netph & 0,1 \\
\hline & Mail & Netma & 0,1 \\
\hline
\end{tabular}

\subsection{Data}

The empirical analysis was done with the 900 active e-mail addresses of Italian SPGs gathered at Retegas, but 126 questionnaires were completed (response rate: 14\%) and five were excluded because of a lack of relevant answers. A total of $64 \%$ of respondents were the president or coordinator of the group. A total of $11 \%$ were product managers, and $11 \%$ were simply members. The remaining respondents were just communication members or founding members. Of the groups that filled out the questionnaire, $94.5 \%$ have a coordinator or a president and $87.5 \%$ have established a board. In $95 \%$ of cases, the members' assembly plays an active role, while $94.5 \%$ of the respondents allocate the tasks of contacting the producer, forwarding orders and managing the distribution of products among members to a product manager. The main activity carried out by the groups that responded is providing food products ( $100 \%$ of the cases). Beyond food, $34.4 \%$ of the groups provided clothing, $68.8 \%$ were engaged in cultural activities, and $29.6 \%$ conducted other activities, including solidarity activities and swap parties. The foundation year and the size of the investigated groups are provided in Table 2. 
Table 2. Year of foundation and size of the SPGs.

\begin{tabular}{ccc}
\hline Year of Foundation & N.Members & N.Groups \\
\hline 1992 & 10 & 1 \\
1997 & 60 & 2 \\
2000 & 34 & 2 \\
2001 & 20 & 3 \\
2002 & 8 & 1 \\
2003 & 20 & 3 \\
2004 & 145 & 10 \\
2005 & 90 & 8 \\
2006 & 63 & 7 \\
2007 & 98 & 7 \\
2008 & 298 & 20 \\
2009 & 383 & 19 \\
2010 & 1116 & 23 \\
2011 & 52 & 6 \\
2012 & 111 & 8 \\
2013 & 100 & 1 \\
\hline
\end{tabular}

\subsection{Data Analysis for Testing $\mathrm{H}_{1}$}

Data analysis was carried out by specific statistical methods. A description of these methods, their explanation and our justification for their use follows. These statistical methods were chosen to allow us to test hypothesis $H_{1}$ and $H_{2}$.

As explained above, we grouped the resource use objectives in three sets: Health, Environment and Convenience, ethical, symbolic and hedonic use values. Therefore, the first step was to test whether each of these sets can be held as a valid construct. Validity is concerned with the extent to which an instrument measures what it is intended to measure. Reliability is concerned with the ability of an instrument to measure consistently: an instrument cannot be valid if it is not reliable [32]. In given samples the construct validity has to be tested. The Cronbach alpha provides a measure of the internal consistency of a test or a scale, i.e., it describes the extent to which all of the items in a test measure the same concept or construct. Hence, alpha is connected to the inter-relatedness of the items within the test [33]. In our study, we determined the Cronbach's alpha and the omega indexes [34-36], the index $\omega_{\mathrm{h}}$ (omega hierarchical). It is defined as the proportional variance in the scale score accounting for a general factor common to all items [36]. The larger it is, the better the reliability. Two related indexes include $\omega_{\text {asymptotic, }}$ which measures omega for an infinite-length test with a structure similar to the observed test, and $\omega_{\mathrm{t}}$ (omega total), which is the proportion of the variance that results from all common factors and offers a direct measure of the internal consistency [37].

We carried out a factor analysis to test the validity of the constructs (Health, Environmental, Convenience, ethical, symbolic and hedonic use values). The factor loadings and the tests are displayed in Table 3 , in which we present the estimated values for alpha and for the omega indexes $\left(\omega_{\mathrm{h}}, \omega_{\text {asymptotic }}\right.$ and $\left.\omega_{t}\right)$.

The values estimated are almost sufficient for alpha in the case of the Health construct and they are sufficient for the Environment construct. On the contrary, the value of alpha for the last construct is below 0.6, indicating that the internal consistency of the construct Convenience, ethical, symbolic and hedonic use values would be poor. The omega indexes provide more information. Although the $\omega_{\mathrm{h}}$ values are not large, we found large values for $\omega_{\text {asymptotic }}$ and $\omega_{\mathrm{t}}$ for both Health and Environment. The results confirm the validity of the two constructs. Again, for the third construct we found a lack of robust evidence: only $\omega_{\text {asymptotic }}$ indicates that in large samples the construct may be internally consistent and valid and that the items considered may be not the causes of the low reliability. In sum, we conclude that the validity of the three constructs appears to be different: while Health and Environment can provide a base for the analysis and the conceptual interpretation of the results, Convenience, ethical, symbolic and 
hedonic use values provides a less reliable base. We will also account for such evidence in the discussion of the results of the empirical analysis.

Table 3. Test of the construct validity.

\begin{tabular}{|c|c|c|c|c|c|}
\hline \multirow{2}{*}{ Resources Uses Objectives } & \multicolumn{5}{|c|}{ Scores } \\
\hline & Mean & Std Dev & Median & Factor Loadings & Tests Values \\
\hline \multicolumn{6}{|l|}{ Health Objectives } \\
\hline SAFETY & 2.844 & 0.369 & 3 & 0.5362 & \\
\hline DIRECTING & 1.065 & 1.526 & 1 & -0.0068 & \\
\hline NORESIDUALS & 2.844 & 0.369 & 3 & 0.7589 & \\
\hline NOPRESERVING ADDIVES & 2.438 & 0.878 & 3 & 0.7332 & \\
\hline KID FOODS & 0.516 & 1.525 & 1 & 0.3414 & \\
\hline Cronbach's Alpha & & & & & 0.6613 \\
\hline Kruskal-Meyer-Olhin & & & & & 0.6648 \\
\hline LR $x 2$ & & & & & $108.97(0.00)$ \\
\hline$\omega_{\mathrm{h}}$ & & & & & 0.66 \\
\hline$\omega_{\text {asymptotic }}$ & & & & & 0.84 \\
\hline$\omega_{t}$ & & & & & 0.78 \\
\hline \multicolumn{6}{|l|}{ Environmental Objectives } \\
\hline ZONE OF PRODUCTION & 2.063 & 0.948 & 2 & 0.3913 & \\
\hline CLOSENESS & 1.969 & 1.177 & 2 & 0.7219 & \\
\hline ENVIRONMENTAL IMPACT & 2.656 & 0.545 & 3 & 0.6552 & \\
\hline LOGISTIC & 2.375 & 0.976 & 3 & 0.6594 & \\
\hline TRADITIONAL GENOTYPES & 1.906 & 0.995 & 2 & 0.3888 & \\
\hline Cronbach's Alpha & & & & & 0.7229 \\
\hline Kruskal-Meyer-Olhin & & & & & 0.669 \\
\hline LR $x 2$ & & & & & $126.16(0.00)$ \\
\hline$\omega_{\mathrm{h}}$ & & & & & 0.62 \\
\hline$\omega_{\text {asymptotic }}$ & & & & & 0.75 \\
\hline$\omega_{t}$ & & & & & 0.83 \\
\hline \multicolumn{6}{|l|}{$\begin{array}{c}\text { Convenience, Ethical, Symbolic } \\
\text { and Hedonic Use Values }\end{array}$} \\
\hline LOWPRICE & 0.938 & 1.190 & 1 & 0.5165 & \\
\hline ETHIC & 2.875 & 0.336 & 3 & 0.0694 & \\
\hline TRADITIONAL FOODS & 1.000 & 1.339 & 1 & 0.5814 & \\
\hline ELABORATED FOODS & -0.276 & 1.623 & 0 & 0.6366 & \\
\hline AVAILABILITY & -0.594 & 1.663 & 0 & 0.4931 & \\
\hline Cronbach's Alpha & & & & & 0.5941 \\
\hline Kruskal-Meyer-Olhin & & & & & 0.695 \\
\hline LR $x 2$ & & & & & $66.49(0.00)$ \\
\hline$\omega_{\mathrm{h}}$ & & & & & 0.48 \\
\hline$\omega_{\text {asymptotic }}$ & & & & & 0.86 \\
\hline$\omega_{t}$ & & & & & 0.56 \\
\hline
\end{tabular}

The next step in analyzing the data involved determining the relationship between the three constructs and communication practices. Our task was then to test whether the action situation variables and the communication practices influenced the resource use objectives. To this end, we used a Generalized Linear Model approach (GLM) [38]. A GLM has three components:

(i) a random component that specifies the conditional distribution of the dependent variable $Y_{i}$ (response variable); the distribution is part of the exponential family (including the Normal, Binomial, and Gamma, for example) and the multinomial family (including the Multinomial distribution);

(ii) a linear predictor:

$$
\eta_{\mathrm{i}}=\alpha+\beta_{1} X_{\mathrm{i} 1}+\beta_{2} X_{\mathrm{i} 2}+\ldots+\beta_{\mathrm{k}} X_{\mathrm{ik}}
$$

where $\eta_{i}$ is the linear predictor; $\alpha, \beta_{1}, \beta_{2} \ldots, \beta_{n}$, are the unknown parameters to be estimated; and $\mathrm{X}_{\mathbf{i}}$, with $i=1, \ldots, \mathrm{n}$ are the independent variables; 
(iii) a link function $g$ that transforms the expectation of the response variable, $\mu_{\mathrm{i}}=\left(\mathrm{Y}_{\mathrm{i}}\right)$, to the linear prediction:

$$
\mathrm{g}\left(\mu_{\mathrm{i}}\right)=\left(\mathrm{Y}_{\mathrm{i}}\right) \eta_{\mathrm{i}}=\mathrm{a}+\beta_{1} \mathrm{X}_{\mathrm{i} 1}+\beta_{2} \mathrm{X}_{\mathrm{i} 2}+\ldots+\beta_{\mathrm{k}} \mathrm{X}_{\mathrm{ik}}
$$

The estimated parameters $\left(\beta_{1}\right)$ determined the influence of the independent variables on the response item and then allowed us to obtain the quantitative measures needed to test hypothesis $H_{1}$.

We estimated a model for each item (response variable): the dependent variable is the assessment made by Likert-scale scores by the respondents (e.g., SAFETY, DIRECTING, etc.). The independent variables are the action situation positions, the communication practice variables and then the types of provisions (see Table 1) are control variables. In the estimation, we treated the dependent variables as if they were continuous variables-an assumption admitted for the seven-point Likert scale $[39,40]$. We then compared the models obtained by two different distributions. We actually estimated the models by assuming a Normal distribution with an "identity" specification for the link function; we also estimated the same models assuming a Gamma distribution with a "log" specification for the link function. We used two different link functions because both of them are compatible with the type of dependent variable we are dealing with. The selection among the models was made by the Bayesian Information Criterion (BIC, [38]).

\subsection{Results of the GLM Estimates}

The models estimated by the assumption of a normal distribution and "identity" as the link function systematically provided a lower BIC, and we have chosen these models. These models turn the approach to linear regression estimates (a special case of the GLM). The dependent variables are the values assigned to each objective (SAFETY, DIRECTING, NORESIDUALS, NOCONSERV, KID_FOODS); the analysis of the results provided information about the quantitative influence of the action situation and communication variables. In the following, we present the results with respect to the three types of variables considered (action situation, control and communication practices variables) that focus particularly on the parameter estimates with a statistical significance that was sufficiently large $(p<0.05, p<0.01$ and $p<0.001)$. The parameter estimates can be interpreted in a simple way: the larger the parameter's estimate for an independent variable, the larger the influence of the variable on the dependent variable. The influence was positive or negative, as indicated by the sign of the estimate. Table 4 illustrates the results for the models concerning the construct of Health. In the model for SAFETY, the influence of the action situation variables was poor, while the Communication practices variables exhibited a more pronounced pattern of influence. Whereas mail contact by the members (Membma) and phone contact by the president (Presph) strongly reduced the values assigned to SAFETY, phone contact by the members and mail and direct contacts by the farmers had a strong positive influence. The selection of farmers able to supply safe food was, in general, an important objective of the SPGs [25]. However, the results indicate that this activity was not directly focused on the action situation, except for the influence of product management. On the contrary, the results indicate that communication practices at the level of both farmers and members determined the identification of this objective. This evidence highlights a different focus on the objective of management and SPG members. The model for DIRECTING accounts for the associated direction, between farmers and the SPG, of the production process. It provides information about the allocation of the decision right of deciding how to use the farm's resources for specific productive tasks. Furthermore, in this case, production management as an action situation variable has a negative impact, whereas there is weak evidence of a positive influence from farmer communication practices (the statistical significance of the parameter estimated is small, with $p<0.1$ ). Therefore, the allocation of decision rights among farmers and SPG consumers appears to not be a relevant resource use objective as expected. However, it is worth underlining that even though the assembly usually plays an important decision-making role [7], there is evidence of a more prominent role of management [25]; our results may be interpreted in this context, 
suggesting that even though joint direction of production may be relevant to some groups, this relevance is not a general trend in the investigated sample. This suggests a difference between the general and specific relevance of the objectives. The role of communication stemming from the SPG network and farmers is also relevant in the case of the NORESIDUALS model: Farmcont, Farmph and Netma increase the average value of the dependent variable, whereas communication by the network (Netcont) has a negative influence. The model for NOCONSERV is of particular interest. All communication practices entailing farmers positively influence the average value, with a prevalence of mail communication. Public authority communication has a weak influence, whereas mail communication by the president has a positive influence. In the case of KID_FOODS, the decisions of the product manager are positively and strongly influential, whereas there is evidence of a negative impact from both the assembly and direct contact by the members. In sum, models in the Health construct confirm the hypothesis that the action situation and communication practices influence health resource use objectives. However, the results also indicate that patterns of influence vary across the model. In the case where general safety issues are more directly of concern (SAFETY and KID_FOODS), both positions and communication practices are influential; in the cases where more specific issues are at stake (NORESID, NOCONSERV), the role of communication practices becomes vital. The rationale for such evidence may be that general issues are much more embedded in a common understanding among SPG members [7], which then shapes positions.

We interpreted these outcomes based on the dynamic nature of the action situation [31] and by the specificity of the codes' definition with respect to the internal coherence of the organization, which is grounded upon the definition of codes [35] upheld in the communication practices. Our analysis cannot tackle these detailed aspects, but only underlines the importance of both action situation positions and communication practices with respect to the resource use objectives.

The Table 5 illustrates the GLM estimates related to environmental concerns. In the model of ZONE OF PRODUCTION, only the communication variable has an influence. Contact-based communication by the president has a positive influence, as does mail communication from farmers and a public authority. A negative impact was estimated to result from network phone contact. Similarly, in the CLOSENESS and TRADITIONAL GENOTYPES models, we only observed an influence from the communication variables. As in the model of Health constructs, we found that the scoring of specific objectives - such as the selection of a given zone of production or the preference for genetic strains associated with cultural heritage-appears to be dependent upon communication. Instead, general purpose objectives tend to entail both the positions in the action situation and the communication practices. It is straightforward to confirm this point by simply detecting the statistically significant variables in the model for ENVIRONMENTAL IMPACT and LOGISTIC.

Table 6 illustrates the models estimated for the last group of resource use objectives. Furthermore, Cloth and Culture have an influence on the objectives. The variables that express the communication practices exhibit an articulated picture across the models. All of these variables have positive and negative impacts. The positive sign prevails in the models for ETHIC and TRADITIONAL FOODS in which the role of farmer communication practices also appears important. The Member and President communication practices have a clear influence on the models of LOWPRICE, ETHIC, and TRADITIONAL FOODS, but only Member practices have an impact on Availability. Finally, we identified an articulated the role of communication activated by the Authority and the Network. 
Table 4. GLM estimates-Health resource use objectives.

\begin{tabular}{|c|c|c|c|c|c|c|c|c|c|c|}
\hline \multirow{3}{*}{ Variables } & \multicolumn{10}{|c|}{ Models } \\
\hline & \multicolumn{2}{|c|}{ SAFETY } & \multicolumn{2}{|c|}{ DIRECTING } & \multicolumn{2}{|c|}{ NORESID } & \multicolumn{2}{|c|}{ NOCONSER } & \multicolumn{2}{|c|}{ KID_FOODS } \\
\hline & Coeff. & $t$ & Coeff. & $t$ & Coeff. & $t$ & Coeff. & $t$ & Coeff. & $t$ \\
\hline Pres & -0.408 & $(-0.92)$ & -0.918 & $(-0.98)$ & -0.278 & $(-0.55)$ & -0.821 & $(-1.33)$ & -1.139 & $(-1.30)$ \\
\hline Manag & 0.262 & $(0.96)$ & -0.669 & $(-1.15)$ & 0.484 & $(1.56)$ & 0.542 & $(1.41)$ & $1.151 *$ & $(2.11)$ \\
\hline Assembly & -0.614 & $(-1.51)$ & -0.0621 & $(-0.07)$ & -0.747 & $(-1.61)$ & -0.822 & $(-1.44)$ & -1.714 * & $(-2.11)$ \\
\hline Prodman & $0.935^{*}$ & $(2.39)$ & $-1.676^{*}$ & $(-2.01)$ & 0.417 & $(0.93)$ & 0.273 & $(0.50)$ & 0.62 & $(0.79)$ \\
\hline Dress & -0.142 & $(-0.96)$ & 0.349 & $(1.10)$ & 0.109 & $(0.64)$ & 0.21 & (1.01) & -0.0487 & $(-0.16)$ \\
\hline Culture & -0.0787 & $(-0.51)$ & 0.106 & $(0.32)$ & 0.0788 & $(0.45)$ & 0.238 & (1.10) & 0.166 & $(0.54)$ \\
\hline Membcont & 0.0161 & $(0.08)$ & 0.392 & $(0.93)$ & -0.188 & $(-0.85)$ & -0.0453 & $(-0.16)$ & $-0.775 *$ & $(-2.00)$ \\
\hline Membph & 0.388 * & (2.10) & -0.178 & $(-0.45)$ & 0.166 & $(0.78)$ & 0.296 & $(-1.14)$ & 0.256 & $(0.69)$ \\
\hline Membma & -0.731 & $(-1.34)$ & -0.143 & $(-0.12)$ & 0.796 & $(1.28)$ & 0.204 & $(-0.27)$ & 0.667 & $(0.61)$ \\
\hline Prescont & -0.0444 & $(-0.20)$ & -0.289 & $(-0.60)$ & 0.148 & $(0.58)$ & -0.243 & $(-0.75)$ & 0.315 & $(0.70)$ \\
\hline Presph & -0.386 & $(-1.83)$ & 0.127 & $(0.28)$ & -0.211 & $(-0.88)$ & -0.463 & $(-1.57)$ & -0.425 & $(-1.01)$ \\
\hline Presma & $0.533 *$ & $(2.27)$ & -0.0408 & $(-0.08)$ & 0.235 & $(0.87)$ & $0.671^{*}$ & $(2.02)$ & 0.305 & $(0.65)$ \\
\hline Farmcont & 0.291 & (1.84) & 0.102 & $(0.30)$ & 0.373 * & $(2.02)$ & 0.527 * & (2.38) & 0.00318 & $(0.01)$ \\
\hline Farmph & 0.19 & (1.37) & 0.494 & (1.65) & $0.412^{* *}$ & $(2.60)$ & 0.497 * & (2.55) & 0.564 * & $(2.03)$ \\
\hline Farmma & 0.401 * & (2.18) & -0.338 & $(-0.83)$ & 0.165 & $(-0.79)$ & 0.593 * & $(2.29)$ & -0.418 & $(-1.14)$ \\
\hline Authcont & 0.0874 & $(0.52)$ & -0.261 & $(-0.73)$ & 0.0292 & $(-0.15)$ & 0.108 & $(0.45)$ & 0.0434 & $(0.13)$ \\
\hline Authph & -0.289 & $(-1.30)$ & -0.221 & $(-0.46)$ & 0.0989 & $(-0.38)$ & 0.308 & $(0.97)$ & 0.52 & $(1.12)$ \\
\hline Automa & 0.115 & $(0.75)$ & 0.493 & $(1.50)$ & -0.321 & $(-1.83)$ & -0.383 & $(-1.79)$ & -0.544 & $(-1.78)$ \\
\hline Netcont & -0.283 & $(-1.50)$ & 0.429 & (1.06) & $-0.471 *$ & $(-2.19)$ & -0.125 & $(-0.47)$ & -0.236 & $(-0.63)$ \\
\hline Netph & -0.109 & $(-0.42)$ & -0.0543 & $(-0.10)$ & 0.328 & $(1.11)$ & -0.205 & $(-0.57)$ & 0.799 & $(1.53)$ \\
\hline Netma & 0.227 & $(0.90)$ & 0.578 & $(1.05)$ & $0.693 *$ & $(2.41)$ & 0.695 & (1.95) & 0.443 & $(0.88)$ \\
\hline _cons & $2.202^{* *}$ & $(-2.71)$ & 3.077 & (1.77) & 0.789 & $(-0.85)$ & 0.794 & $(0.70)$ & 0.932 & $(0.58)$ \\
\hline $\mathrm{N}$ & 123 & & 121 & & 122 & & 122 & & 121 & \\
\hline Loglikelihood & -11.2 & & -205.6 & & -130.91 & & -156.39 & & -197.43 & \\
\hline AIC & 2.25 & & 3.76 & & 2.59 & & 33635.00 & & 3.63 & \\
\hline $\mathrm{BIC}$ & -438.38 & & -262.8 & & -419.30 & & -387.65 & & -289.61 & \\
\hline$t$ statistics in & rentheses & & & & & & & & & \\
\hline
\end{tabular}

${ }^{*} p<0.05,{ }^{* *} p<0.01,{ }^{* * *} p<0.001$ 
Table 5. GLM estimates-Environmental resource use objectives.

\begin{tabular}{|c|c|c|c|c|c|c|c|c|c|c|}
\hline \multirow{3}{*}{ Variables } & \multicolumn{10}{|c|}{ Models } \\
\hline & \multicolumn{2}{|c|}{$\begin{array}{c}\text { ZONE OF } \\
\text { PRODUCTION }\end{array}$} & \multicolumn{2}{|c|}{ CLOSENESS } & \multicolumn{2}{|c|}{$\begin{array}{l}\text { ENVIRONMENTAL } \\
\text { IMPACT }\end{array}$} & \multicolumn{2}{|c|}{ LOGISTIC } & \multicolumn{2}{|c|}{$\begin{array}{l}\text { TRADITIONAL } \\
\text { GENOTYPES }\end{array}$} \\
\hline & Coeff. & $t$ & Coeff. & $t$ & Coeff. & $t$ & Coeff. & $t$ & Coeff. & $t$ \\
\hline Pres & 0.412 & $(-1.08)$ & 0.203 & $(-0.59)$ & 0.13 & $(0.57)$ & -0.104 & $(-0.41)$ & -0.144 & $(-0.31)$ \\
\hline Manag & -0.0185 & $(-0.09)$ & -0.109 & $(-0.46)$ & -0.281 & $(-1.66)$ & -0.108 & $(-0.44)$ & -0.392 & $(-1.24)$ \\
\hline Assembly & -0.103 & $(-0.34)$ & -0.188 & $(-0.72)$ & -0.0473 & $(-0.18)$ & -0.306 & $(-1.17)$ & -0.293 & $(-0.88)$ \\
\hline Prodman & -0.251 & $(-0.90)$ & 0.0798 & $(-0.32)$ & 0.0516 & $(0.32)$ & 0.286 & $(1.73)$ & 0.304 & $(1.05)$ \\
\hline Dress & 0.0972 & $-(0.58)$ & 0.0298 & $(-0.16)$ & -0.0616 & $(-0.39)$ & 0.137 & $(0.75)$ & -0.0366 & $(-0.16)$ \\
\hline Culture & -0.187 & $(-0.88)$ & -0.178 & $(-0.77)$ & 0.0337 & $(0.17)$ & 0.0502 & $(0.24)$ & -0.0789 & $(-0.36)$ \\
\hline Membcont & -0.301 & $(-1.05)$ & 0.204 & $(-0.84)$ & -0.101 & $(-0.48)$ & -0.067 & $(-0.38)$ & -0.0733 & $(-0.24)$ \\
\hline Membph & -0.114 & $(-0.52)$ & 0.162 & $(-0.57)$ & 0.483 * & $(1.98)$ & $0.712 *$ & $(2.31)$ & $1.280^{* * *}$ & $(3.57)$ \\
\hline Membma & -0.157 & $(-0.50)$ & 1.214 & $(-0.91)$ & 0.823 & $(0.82)$ & 1.093 & $(0.87)$ & -0.104 & $(-0.16)$ \\
\hline Prescont & 0.598 & $(1.85)$ & 0.114 & $(-0.35)$ & 0.227 & $(0.92)$ & 0.144 & $(0.72)$ & 0.152 & $(0.50)$ \\
\hline Presph & -0.218 & $(-0.87)$ & -0.49 & $(-1.36)$ & -0.639 * & $(-2.17)$ & $-1.135^{* * *}$ & $(-3.53)$ & $-1.254^{* * *}$ & $(-3.31)$ \\
\hline Presma & -0.123 & $(-0.33)$ & 0.128 & $(-0.33)$ & 0.451 & $(-1.44)$ & 0.568 & $(1.64)$ & 0.25 & $(0.60)$ \\
\hline Farmcont & -0.0773 & $(-0.39)$ & 0.209 & $(-0.99)$ & 0.469 & $(1.94)$ & 0.367 & (1.20) & 0.314 & (1.15) \\
\hline Farmph & 0.0935 & $-(0.48)$ & 0.159 & $(-0.77)$ & 0.219 & (1.52) & 0.472 * & $(2.17)$ & 0.464 & (1.68) \\
\hline Farmma & $0.428 *$ & $(2.06)$ & -0.175 & $(-0.59)$ & 0.36 & (1.37) & 0.26 & $(0.79)$ & 0.126 & (0.39) \\
\hline Authcont & -0.227 & $(-1.20)$ & -0.186 & $(-0.81)$ & 0.101 & $(0.66)$ & -0.0681 & $(-0.31)$ & -0.173 & $(-0.50)$ \\
\hline Authph & 0.019 & $(-0.10)$ & $0.668^{*}$ & $(2.28)$ & 0.288 & (1.48) & 0.304 & $(1.04)$ & 0.0268 & $(0.06)$ \\
\hline Automa & $0.725^{* * *}$ & $(3.77)$ & 0.0805 & $(-0.37)$ & -0.282 & $(-1.38)$ & -0.0366 & $(-0.19)$ & 0.051 & (0.18) \\
\hline Netcont & 0.356 & $-(1.63)$ & 0.325 & $(-1.29)$ & -0.221 & $(0.76)$ & -0.351 & $(-1.20)$ & 0.0932 & $(0.24)$ \\
\hline Netph & -0.540 * & $(-2.13)$ & $-1.301^{* * *}$ & $(-3.46)$ & -0.0461 & $(-0.20)$ & -0.541 & $(-1.43)$ & -0.103 & $(-0.23)$ \\
\hline Netma & -0.232 & $(-0.61)$ & 0.311 & $-(0.85)$ & 0.291 & $(0.82)$ & 0.378 & $(0.75)$ & $1.535^{* * *}$ & $(3.67)$ \\
\hline _cons & $1.909^{* *}$ & $-(2.62)$ & 0.456 & $-(0.32)$ & 0.839 & $(0.76)$ & 0.185 & $(0.14)$ & 0.151 & (0.13) \\
\hline $\mathrm{N}$ & 106 & & 107 & & 107 & & 106 & & 105 & \\
\hline Loglikeihood & -135.82 & & -145.17 & & -122.49 & & -141.15 & & -160.08 & \\
\hline AIC & 2.98 & & 3.12 & & 2.7 & & 3.08 & & 3.47 & \\
\hline $\mathrm{BIC}$ & -311.23 & & -302.71 & & -335.34 & & -302.72 & & -256.5 & \\
\hline
\end{tabular}

$t$ statistics in parentheses; ${ }^{*} p<0.05,{ }^{* *} p<0.01,{ }^{* * *} p<0.001$. 
Table 6. GLM estimates-Convenience, ethical, symbolic and hedonic use values.

\begin{tabular}{|c|c|c|c|c|c|c|c|c|c|c|}
\hline \multirow{2}{*}{ Variables } & \multicolumn{2}{|c|}{ LOWPRICE } & \multicolumn{2}{|c|}{ ETHIC } & \multicolumn{2}{|c|}{$\begin{array}{c}\text { Models } \\
\text { TRADITIONAL FOODS }\end{array}$} & \multicolumn{2}{|c|}{ ELABORATED FOODS } & \multicolumn{2}{|c|}{ AVAILABILITY } \\
\hline & Coeff. & $t$ & Coeff. & $t$ & Coeff. & $t$ & Coeff. & $t$ & Coeff. & $t$ \\
\hline Pres & -0.203 & $(-0.28)$ & -0.159 & $(-0.33)$ & -0.37 & $(-0.48)$ & 0.421 & $-(0.45)$ & -0.734 & $(-1.13)$ \\
\hline Manag & 0.513 & $-(0.98)$ & $-1.412^{* * *}$ & $(-3.78)$ & 0.924 & $-(1.24)$ & 0.438 & $-(0.64)$ & 0.688 & $-(1.52)$ \\
\hline Assembly & -0.36 & $(-0.49)$ & 0.291 & $-(0.65)$ & -0.802 & $(-1.36)$ & -0.541 & $(-0.77)$ & $-1.634^{*}$ & $(-2.45)$ \\
\hline Prodman & 0.154 & $-(0.18)$ & $-1.770^{* * *}$ & $(-3.82)$ & -0.481 & $(-0.60)$ & -0.543 & $(-0.48)$ & -0.338 & $(-0.49)$ \\
\hline Dress & 0.469 & $-(1.71)$ & 0.154 & $-(0.52)$ & 0.694 * & $-(2.35)$ & 0.772 * & $-(2.44)$ & 0.414 & $-(1.33)$ \\
\hline Culture & -0.661 * & $(-2.47)$ & 0.21 & $-(0.66)$ & -0.551 & $(-1.79)$ & $-0.674 *$ & $(-2.12)$ & -0.382 & $(-1.17)$ \\
\hline Membcon & -0.446 & $(-1.31)$ & 0.389 & $-(0.94)$ & -0.577 & $(-1.55)$ & -0.532 & $(-1.41)$ & -0.32 & $(-0.75)$ \\
\hline Membph & $0.989^{* *}$ & $-(2.91)$ & $-0.843^{*}$ & $(-2.30)$ & 0.404 & $-(1.06)$ & $0.997^{*}$ & $-(2.46)$ & 0.312 & $-(0.81)$ \\
\hline Membma & -0.447 & $(-0.67)$ & -0.355 & $(-0.34)$ & 1.325 * & $-(2.21)$ & 1.364 & $-(1.22)$ & $3.361 * *$ & $-(3.02)$ \\
\hline Prescont & 0.408 & $-(0.98)$ & -0.372 & $(-0.80)$ & 0.891 & $-(1.90)$ & 0.69 & $-(1.43)$ & 0.136 & $-(0.28)$ \\
\hline Presph & -0.346 & $(-0.94)$ & 0.583 & $-(1.38)$ & -0.0837 & $(-0.19)$ & -0.661 & $(-1.51)$ & 0.00808 & $-(0.02)$ \\
\hline Presma & 0.147 & $-(0.31)$ & -0.244 & $(-0.50)$ & -0.72 & $(-1.47)$ & -0.0233 & $(-0.05)$ & -0.224 & $(-0.41)$ \\
\hline Farmcon & -0.0656 & $(-0.19)$ & 0.473 & $-(1.51)$ & -0.0193 & $(-0.05)$ & -0.118 & $(-0.33)$ & -0.248 & $(-0.76)$ \\
\hline Farmph & -0.00326 & $(-0.01)$ & 0.456 & $-(1.56)$ & 0.0937 & $-(0.35)$ & 0.265 & $-(0.90)$ & 0.396 & $-(1.37)$ \\
\hline Farmma & $0.995^{* *}$ & $-(2.61)$ & $-0.825 *$ & $(-2.42)$ & 0.981 * & $-(2.47)$ & $1.563^{* * *}$ & $-(3.41)$ & 0.215 & $-(0.68)$ \\
\hline Authcont & 0.408 & $-(1.87)$ & -0.011 & $(-0.03)$ & 0.318 & $-(1.00)$ & 0.522 & $-(1.57)$ & 0.48 & $-(1.66)$ \\
\hline Authph & -0.243 & $(-0.71)$ & -0.137 & $(-0.34)$ & -0.0351 & $(-0.07)$ & 0.5 & $-(1.10)$ & $1.043^{* *}$ & $-(2.91)$ \\
\hline Automa & 0.0177 & $-(0.05)$ & $0.721 *$ & $-(2.23)$ & -0.551 & $(-1.59)$ & $-0.791 *$ & $(-2.33)$ & $-0.805^{*}$ & $(-2.31)$ \\
\hline Netcont & 0.0862 & $-(0.21)$ & -0.0545 & $(-0.17)$ & -0.0608 & $(-0.14)$ & 0.072 & $-(0.16)$ & -0.223 & $(-0.63)$ \\
\hline Netph & -0.574 & $(-1.67)$ & 0.446 & $-(0.98)$ & -0.607 & $(-1.12)$ & -0.97 & $(-1.82)$ & -0.109 & $(-0.17)$ \\
\hline Netma & 0.0658 & $-(0.15)$ & 0.432 & $-(0.93)$ & 0.903 & $-(1.79)$ & 0.76 & $-(1.43)$ & $0.926 *$ & $-(2.33)$ \\
\hline _cons & 1.721 & $-(1.35)$ & $3.879 * *$ & $-(3.07)$ & 0.68 & $-(0.57)$ & -1.182 & $(-0.76)$ & -1.585 & $(-1.14)$ \\
\hline $\mathrm{N}$ & 123 & & 122 & & 122 & & 118 & & 121 & \\
\hline Loglikelihood & -198.99 & & -304 & & -207.25 & & -207.45 & & -212.87 & \\
\hline AIC & 3.59 & & 3.85 & & 3.76 & & 3.81 & & 3.88 & \\
\hline $\mathrm{BIC}$ & -302.93 & & -246.1 & & -266.9 & & -225.48 & & -235.79 & \\
\hline
\end{tabular}

Data analysis for testing $\mathrm{H}_{2}$ : Coproduction of health and environmental services. ${ }^{*} p<0.05,{ }^{* *} p<0.01,{ }^{* * *} p<0.001$. 
This evidence confirms the complexity of the positions and organizational practices. Both of these factors influence the definition of the objective and group coherence [35]. Also, the models of this last group can be discriminated in terms of the types of statistically significant variables. Models concerning specific issues-such as price or the preference for specific types of food-provide evidence of the influence of the communication variables. The more general issues models, such as ETHIC and AVAILABILTY, also indicate the influential role of the action situation variables. However, it may be questionable to conclude that all three groups of models provide convergent evidence, despite the common pattern of results. The reason is that the last construct, Convenience, ethical, symbolic and hedonic use values, is not fully reliable.

Due to differences in terms of validity, the three constructs cannot provide a homogeneous perspective. We point out that the results interpretation for Health and Environment protection can be held as based on valid constructs. There, in these cases, the models for the corresponding items provide information that concerns internally consistent constructs. This partially holds for the construct Convenience, ethical, symbolic and hedonic use values. In this case, the models estimated for each item may be not informative about a consistent construct. Although this is a limit of the empirical analysis, it does not imply that a comparison cannot be made between the first two constructs and the objectives considered by the items included in Convenience, Ethic and Tradition. Moreover, on the basis of our evidence, we cannot exclude the hypothesis that in large sample the construct is valid.

To test hypothesis $\mathrm{H}_{2}$ we considered the means of the scores assigned by the respondent to each resource use objective as grouped in the three constructs. The means were calculated as follows. Considering $K$ items for each construct, the mean score $S_{j k}$ for the $k$.th (where $k=1,2 \ldots K$ ) item of the $j . t h$ (where $j=1,2,3$ ) construct (e.g., Health) is:

$$
s_{j k}=\frac{1}{Z} \sum_{z} s_{j k z}
$$

where $z=1,2, \ldots Z$ indicates the $z . t h$ respondent (group) and $S_{j k z}$ is the score assigned by the $z$.th respondent to the $k$.th item of the $j$.th construct. Therefore, the mean score assigned to the $j . t h$ construct is:

$$
S_{j}=\frac{1}{K} \sum_{z} s_{i k}
$$

We have to reject $H_{2}$ if:

$$
S_{\text {HEALTH }}<S_{C O N V}
$$

and

$$
S_{E N V I R}<S_{C O N V}
$$

where $S_{H E A L T H}$ is the mean score for Health, $S_{E N V I R}$ is the mean score for Environment and $S_{C O N V}$ is the mean score for Convenience, ethical, symbolic and hedonic use values.

To test $\mathrm{H}_{2}$, we firstly tested the significance of the means $\mathrm{S}_{j}$ and then we ascertained that the comparisons - made by mean differences-are statistical significant. To this purpose we calculated the $t$-statistic for each difference [41]. Finally, we compared the statistical significant means differences with the expected inequalities in Equations (6) and (7).

The mean values achieved by the three sets of objectives are as follows: $1.80(t=2.56(0.01))$ for Health; $2.13(t=3.16(0.001))$ for Environment; and $1.53(t=1.64(0.10))$ for the other objectives (Convenience, ethical, symbolic and hedonic). In Table 7, we show the test of differences between the means of the values in each set. 
Table 7. Mean differences of the values assigned to the resource use objectives.

\begin{tabular}{|c|c|c|c|}
\hline Means Differences & $t$ Statistic & Degrees of Freedom & $p$ Value \\
\hline \multicolumn{4}{|l|}{ Health-Environment } \\
\hline$S_{\text {HEALTH }}-S_{E N V I R}<0$ & -4.039 & 109 & 0.0001 \\
\hline$S_{H E A L T H}-S_{E N V I R}=0$ & -4.011 & 109 & 0.0001 \\
\hline$S_{H E A L T H}-S_{E N V I R}>0$ & 0.0001 & 109 & 0.9999 \\
\hline \multicolumn{4}{|c|}{ Health-Convenience, Ethic, Symbolic and Hedonic } \\
\hline$S_{\text {HEALTH }}-S_{C O N V}<0$ & 0.0001 & 115 & 0.9999 \\
\hline$S_{\text {HEALTH }}-S_{C O N V}=0$ & 3.767 & 115 & 0.0003 \\
\hline$S_{\text {HEALTH }}-S_{C O N V}>0$ & 4.03 & 115 & 0.0001 \\
\hline \multicolumn{4}{|l|}{ Environment-Other Values } \\
\hline$S_{E N V I R}-S_{C O N V}<0$ & 0.000 & 114 & 1.000 \\
\hline$S_{E N V I R}-S_{C O N V}=0$ & 6.040 & 114 & 0.000 \\
\hline$S_{E N V I R}-S_{C O N V}>0$ & 6.180 & 114 & 0.000 \\
\hline
\end{tabular}

All three mean differences are statistically significa-nt, indicating that the respondents are able to discriminate among the set of objectives. It is also evident that $S_{H E A L T H} \geqslant S_{C O N V}$ and $S_{E N V I R} \geqslant S_{C O N V}$. Therefore, given the mean score comparisons, we have to not reject $\mathrm{H}_{2}$.

Moreover, in Figures $2-4$ we summarized the distribution of the values. The Graphics are boxplots [42]: the highest and the lowest side of the boxplot are, respectively, the third and the first quartile. The central line is the median of the distribution. Therefore, boxplots 1, 2 and 3 illustrate the dispersion of the data, the symmetry and the potential outliers (data out of the box). In the Health group graphic, except for four outliers, a score of 3 was assigned to SAFETY and NORESIDUAL. A total of $50 \%$ of the respondents assigned a score between 0 and 2 to DIRECTING. In the case of NOCONSERV, the second $25 \%$ of the sample assigned a value between 2 and 3 , whereas the third quartile assigned a value equal to 3 . The score of KID_FOODS was lower. The scores assigned to the objectives of the Environment group were all between 2 and 3, except for TRADITIONAL GENOTYPES (1-2). The scores assigned to Other Objectives were lower than the previous case, except for LOWPRICE. The third 25\% in the case of ETHIC assigned scores between 1 and 3, indicating larger variance. The scores were higher for TRADITIONAL FOODS. In the case of ELABORATED FOODS, $25 \%$ of the respondents included between the first and second quartile assigned a value between 1 and 2; the subsequent $25 \%$ valued the objective between 2 and 3 . The variability of the score assigned by the third $25 \%$ was higher than in the case of AVAILABILITY.

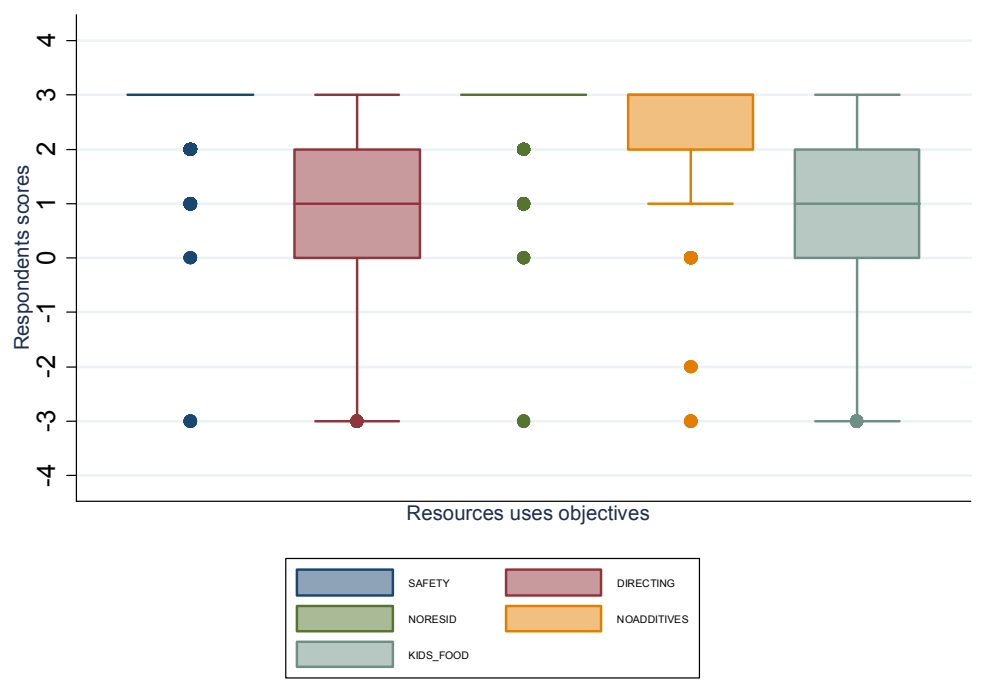

Figure 2. Evaluation of the health resource uses objectives. 


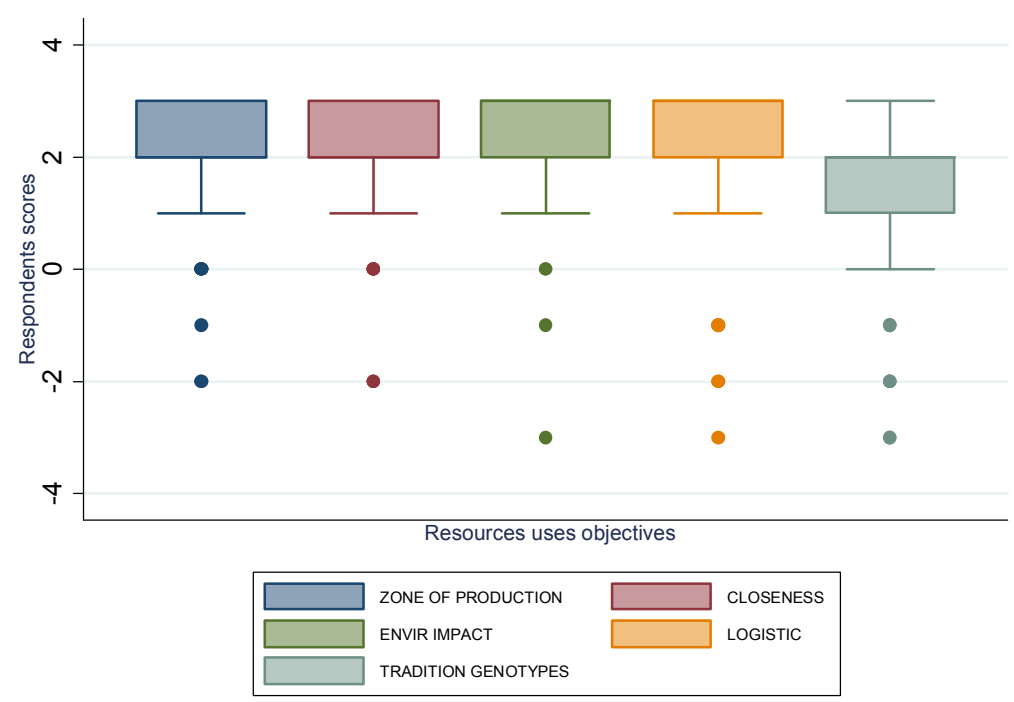

Figure 3. Evaluation of the environmental resources uses objectives.

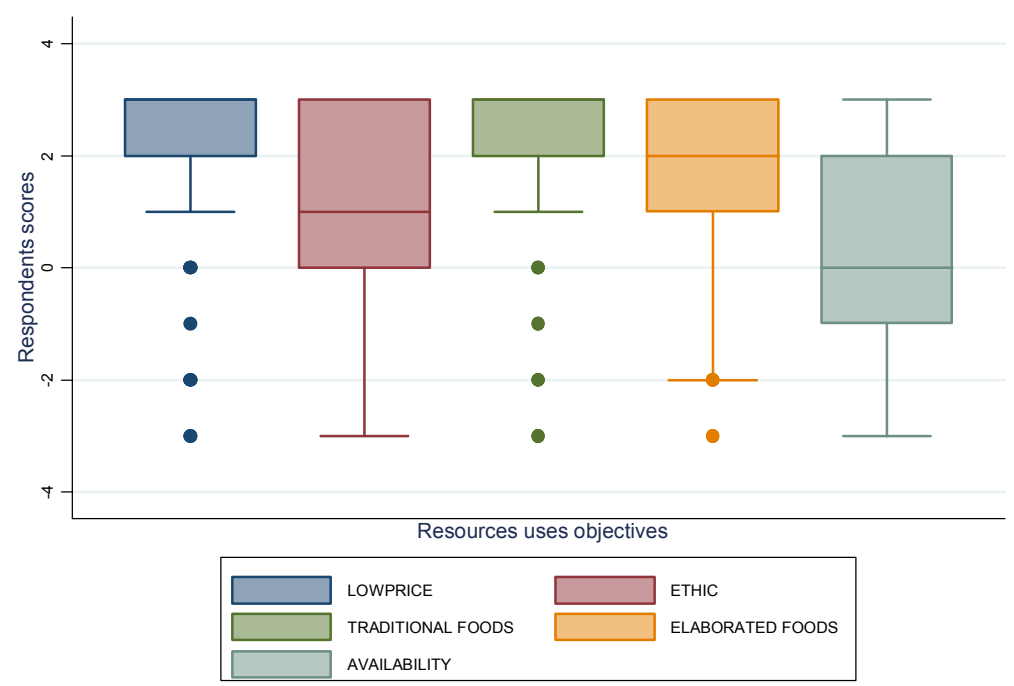

Figure 4. Convenience, ethical, symbolic and hedonic objectives.

We also measured the asymmetry of the data distribution by comparing the difference between the third quartile and the median, and the median and the first quartile. In the case of Health objectives, we found the distribution was symmetric for SAFETY and NORESIDUAL (with the highest value of 3). The distribution is also symmetric for KID_FOODS, but the values were lower. We found an asymmetric distribution for DIRECTING, with a concentration among the values of 1 and 0 ; we found an asymmetric distribution for NOCONSERV, but with a concentration between 3 and 2 .

In sum, the values assigned to health and environmental resource use objectives were larger and less variable. On the contrary, the values assigned to the other resource use objectives were smaller and more variable. We then concluded that the groups tended to define their objectives mainly based on health and environmental outcomes.

\section{Discussion}

The results of the empirical analysis led us to confirm both hypotheses $H_{1}$ and $H_{2}$. This evidence first confirms the shift in focus from food per se towards food as a means of integrating multiple dimensions (especially health and environmental protection in this case). More precisely, in our study, 
we found that communication practices influence resource use objectives; in turn, these objectives can be considered as the core of the development of the organizational constituting processes [8], which is part of the structure. The practices are part of the organizational establishment [15]. The evidence gathered about the two hypotheses indicates that the SPG sets up an organization, assigning a prevalent importance to health and environmental protection objectives, and aims at contributing, with public actors engaged in the provisioning of health services, and promoting and regulating the environment (this includes regional, national and supranational agencies and public authorities) [43] to co-produce health and environmental values.

Originally addressed by [25] and developed in a specialized field by [43,44], the capability for co-production by SPGs has been confirmed by this study. In this context, the first implication of our study is that the SPGs exhibit a capability for ranking resource use objectives with respect to health and environmental protection related to food production and consumption. This ability is rooted in the practice-structure interplay [23]. An SPG could then engage in programs of activities explicitly aimed at achieving health and environmental outcomes on the scale at which they operate. Of course, the ability to rank objectives does not guarantee that the objectives will be achieved in reality. The second implication of our study that we would like to stress relates to the nature of the considered objectives. The study in [43] showed how a local group undertakes the coproduction of specific services. Nonetheless, despite the "healthy" content of these services, this approach differs from the objectives in our study. In fact, the common good nature of such objectives requires the design of adequate working rules [31]. The absence of such rules may reduce the incentives of the group seeking to achieve specific objectives.

The results confirm the importance of the organizational dimensions in two basic ways. First, the results confirm the nexus examined by [24] between the SPG food practices and group coordination. Second, the study shows that the communication practices contribute to learning in a dynamic fashion, sustaining organizational development $[8,15]$ and, from an analytical viewpoint, highlighting the role of the organization as a means of connecting food, health, and, especially, the environment [7].

Moreover, the difference between the general and specific objectives identified in the data analysis suggests that the intentional design of communication practices may favor the improvement of the organizational dimensions Second, the results indicate differences among the positions. In each concrete situation, it may be useful to assess these differences and to potentially modify them, if possible, in order to enhance group effectiveness in the provision of goods and services. The regulatory framework may constrain the group's activity and its innovation capability [7] may be insufficient. Examples can be found in the Italian experience where a regional regulation more concerned with local economies seems to have enlarged the scope of group activities, as documented by [25].

Four problems may arise in the design of an SPG organization aimed at the co-production of health and environmental protection. The first problem concerns the difficulty of efficiently negotiating the allocation of decision rights between the SGP and farmers. Scholars $[8,18]$ state that the parties of an arrangement can efficiently negotiate when they are facing a level of uncertainty-e.g., concerning the quality of food in our case-with which they cannot cope without an adequate arrangement. Therefore, if farmers can design such an arrangement with a better partner, the SPG may encounter such a negotiation difficulty and an agreement with farmers may be not adopted. The second problem derives from the knowledge required of the SPG; unfortunately, technological knowledge about food systems is often specialized in nature, and this may limit the SPG. Third, the economic and geographic scale of the SPG must be noted. The scales are both inherently limited. Although the organizational arrangement may support effective coordination, complex organizations requiring enlarged scales of provisioning must be recognized as exceeding the SPG capabilities. The fourth problem has already been mentioned and concerns the potential constraints of the regulatory framework. Finally, the results also show that the allocation of the decision rights matters, but it is not of high importance. Our interpretation is that the size of transaction costs raised by the uncertainty should be not so large as to push the farmers to allocate to the consumers' relevant decision rights. 


\section{Final Remarks}

This study concentrated on Italian SPGs and aimed to examine SPGs as emerging organizations that engage in the provision of food and also focus on specific dimensions of food. Health and environmental protection are among the intended outcomes of the SPGs' / public authorities' co-production initiatives. Accordingly, the groups' decision-making processes tend to assume a polycentric architecture. Communicative practices have a basic role in establishing the arrangements that sustain the SPG. We adopted an organizational perspective and hypothesized that the practices of the SPG contribute to determining the rank of the resource use objectives needed and their complementarity. The constitutional processes undertaken by the SPGs and farmers are influenced by health and environmental objectives. From an analytic perspective, this study emphasizes the possibility of connecting the institutional analysis of co-production [29] with the constitutional analysis of the organization. The main limitations of the study arise from a focus on the average evaluation at a group level. While it appears reasonable that the SPGs tend to undertake collective action, it is also true that the variability of the evaluation within the group may influence strategy implementation. Specific attention to this point may be the focus of future studies. A more comprehensive empirical analysis is also necessary to investigate how specific classes of resources are allocated to different objectives. This analysis would first provide a basis for enhancing the conceptual framework by highlighting how the allocation of decision rights in the polycentric context sustains the achievement of group goals. A promising line of inquiry could also address the role of farms and food companies in co-production activities that are triggered by the SPGs, compared with processes undertaken autonomously by farms and companies seeking to implement sustainable strategies.

Acknowledgments: An early version of this study was presented at the session (Re-)establishing economic "societas": right sharing based forms of organizing held at the 5th LAEMOS Colloquium Latin American and European Meeting on Organization Studies. We wish to thank Anna Grandori (Bocconi University, Milan, Italy) and all the participants in the session. Usual caveats apply. The research was carried out by funds granted by the Agreements CNR-UNIPG-Progetto FFW European Union Com Grant n. 308733.

Author Contributions: Gaetano Martino conceived and designed the study and the method of empirical analysis. $\mathrm{He}$ also carried out the statistical analysis, defined the structure of the argument and wrote the paper. Giulia Giacchè revised and finalized the data analysis; she contributed to the argument structuring and to the comments on statistical results. Enrica Rossetti designed the questionnaire, managed the data collection, selected the data useful for analysis and carried out the data descriptive analysis and revised the text.

Conflicts of Interest: The authors declare no conflict of interest. The founding sponsors had no role in the design of the study; in the collection, analyses, or interpretation of data; in the writing of the manuscript, and in the decision to publish the results.

\section{Abbreviations}

SPG solidarity purchasing group

SPGs solidarity purchasing groups

\section{References}

1. Stefano, P. Governance structure, perception, and innovation in credence food transactions: The role of food community networks. Int. J. Food Syst. Dyn. 2010, 1, 224-236.

2. Lamine, C. Sustainability and Resilience in Agrifood Systems: Reconnecting Agriculture, Food and the Environment. Sociol. Rural. 2015, 55, 41-61. [CrossRef]

3. Renting, H.; Marsden, T.K.; Banks, J. Understanding alternative food networks: Exploring the role of short food supply chains in rural development. Environ. Plan. 2003, 35, 339-411. [CrossRef]

4. Marsden, T.; Sonnino, R. Alternative food network in the south-wedt of England: Towards a new agrarian eco-economy? In Between the Local and the Global: Confronting Complexity in the Contemporary Agri-Food Sector; Marsden, T., Murdoch, J., Eds.; Elsevier: Oxford, UK, 2006.

5. Bougherara, D.; Grolleau, G.; Mzoughi, N. Buy local, pollute less: What drives house-holds to join a community supported farm? Ecol. Econ. 2009, 68, 1488-1495. 
6. Forssell, S.; Lankoski, L. The sustainability promise of alternative food networks: An examination through "alternative" characteristics. Agric. Hum. Values 2015, 32, 63-74. [CrossRef]

7. Brunori, G.; Rossi, A.; Guidi, F. On the New Social Relations around and beyond Food. Analysing Consumers' Role and Action in Gruppi di Acquisto Solidale (Solidarity Purchasing Groups). Sociol. Rural. 2012, 52, 1-30. [CrossRef]

8. Grandori, A. Asset commitment, constitutional governance and the nature of the firm. J. Inst. Econ. 2010, 6, 351-375. [CrossRef]

9. Grasseni, C. Seeds of trust. Italy's Gruppi di Acquisto Solidale (Solidarity Purchase Groups). J. Political Ecol. 2014, 211, 78-192.

10. Brunori, G.; Rossi, A.; Malandrin, V. Co-producing transition: Innovation processes in farms adhering to solidarity-based purchase groups (GAS) in Tuscany, Italy. Int. J. Sociol. Agric. Food 2011, 18, $28-53$.

11. Ostrom, V.; Tiebout, C.M.; Warren, R. The organization of the government in metropolitan areas: A theoretical inquiry. Am. Political Sci. Rev. 1961, 55, 831-842. [CrossRef]

12. Ostrom, E. Crossing the great divide: Coproduction, synergy and development. World Dev. 1996, 24, 1073-1087. [CrossRef]

13. Pretty, J. Agricultural sustainability: Concepts, principles and evidence. Philos. Trans. B 2008, 363, 447-465. [CrossRef] [PubMed]

14. Warde, A. Consumption and theory of practice. J. Consum. Cult. 2005, 5, 131-153. [CrossRef]

15. Grandori, A.; Furnari, S. A chemistry of organization: Combinatory analysis and design. Organ. Stud. 2008, 29, 315-341. [CrossRef]

16. Gradwell, S. Community Supported Agriculture: Local Food Systems for Iowa; Iowa State University: University Extension, 1999. Available online: https://store.extension.iastate.edu/Product/Local-FoodSystems-for-Iowa-Community-Supported-Agriculture (accessed on 14 March 2016).

17. Graziano, P.R.; Forno, F. Political Consumerism and New Form of political participation: The gruppi di acquisto solidade in Italy. Ann. Am. Acad. Political Soc. Sci. 2012, 664, 121-133. [CrossRef]

18. Menard, C. Hybrid Modes of Organization. Alliances, Joint Ventures, Networks, and Other "Strange" Animals. In The Handbook of Organizational Economics; Princeton University Press: Princeton, NJ, USA; Oxford, UK, 2013; pp. 1066-1108.

19. Jones, A.; Murphy, J.T. Theorizing practice in economic geography. Foundation, challenges and possibilities. Prog. Hum. Geogr. 2010, 35, 366-392. [CrossRef]

20. Sahakian, M.; Wilhite, H. Making practice theory practicable: Towards more sustainable forms of consumption. J. Consum. Cult. 2014, 14, 25-44. [CrossRef]

21. Gray, B.; Purdy, J.M.; Ansari, S.S. From interactions to institutions: Microprocesses of framing and mechanisms for the structuring of institutional fields. Acad. Manag. Rev. 2015, 40, 115-143. [CrossRef]

22. Entman, R.M. Framing: Towards clarification of a fractured paradigm. J. Commun. 1993, 43, 390-397. [CrossRef]

23. Delormier, T.; Frohlich, K.L.; Potvin, L. Food and eating as social practice-understanding eating patterns as social phenomena and implications for public health. Sociol. Health Illn. 2009, 31, 215-228. [CrossRef] [PubMed]

24. Fonte, C.M. Food consumption as social practice: Solidarity Purchasing Groups in Rome, Italy. J. Rural Stud. 2013, 32, 230-239.

25. Martino, G.; Pampanini, R.; Giacchè, G. Exploring the role of consumers as drivers of agri-food networks: Contexts, beliefs, and governance. Braz. Geogr. J. Geosci. Humanit. Res. Medium 2013, 4, 122-137.

26. Goodman, D.; DuPuis, M.E. Knowing food and growing food: Beyond the production-consumption debate in the sociology of agriculture. Sociol. Rural. 2002, 42, 5-22.

27. Marsden, T.; Banks, J.; Bristow, G. Food Supply Chain Approaches: Exploring Their Role in Rural Development. Sociol. Rural. 2000, 40, 424-438. [CrossRef]

28. Grasseni, C.; Forno, F.; Signori, S. Beyond alternative Food Networks. An Agenda for Comparative Analysis of Italy's Solidarity Purchase Groups (GAS) and Districts of Solidarity Economy (DES) vis-à-vis US Community Economies. In Proceedings of the Draft Paper Prepared for the UNRISD Conference Potential and Limits of Social and Solidarity Economy, Geneva, Switzerland, 6-8 May 2013; Available online: http:/ / www.unrisd.org/80256B3C005BCCF9/(httpAuxPages)/2C9AC13AE549A8BBC1257B5F005DABDE (accessed on 12 March 2016). 
29. Fowler Floyd, J., Jr. Survey Research Methods; Sage Publications: Los Angeles, CA, USA, 2013.

30. Gehlbach, H.; Barge, S. Anchoring and Adjusting in Questionnaire Responses. Basic Appl. Soc. Psychol. 2012, 34, 417-433. [CrossRef]

31. Ostrom, E. Understanding Institutional Diversity; Princeton University Press: Princeton, NJ, USA, 2005.

32. Tavakol, M.; Dennick, R. Making sense of Cronbach's alpha. Int. J. Med. Educ. 2011, 2, 53-59.

33. Cronbach, L.J. Coefficient alpha and the internal structure of the tests. Psychometrica 1951, 16, $297-334$. [CrossRef]

34. Westen, D.; Rosenthal, R. Quantifying construct validity: Two simple measures. J. Personal. Soc. Psychol. 2003, 84, 608-618. [CrossRef]

35. Brunori, G.; Rossi, A. Synergy and Coherence through Collective Action: Some Insights from Wine Routes in Tuscany. Sociol. Rural. 2000, 40, 402-423. [CrossRef]

36. Zinbarg, R.E.; Revelle, W.; Yovel, I.; Li, W. Cronbach's $\alpha$, Revelle's $\beta$, and McDonald's $\omega$ H: Their relations with each other and two alternative conceptualizations of reliability. Psychometrika 2005, 70, 123-133. [CrossRef]

37. Revelle, W.; Zinbarg, R.E. Coefficients alpha, beta, omega, and the glb: Comments on Sijtsma. Psychometrika 2009, 74, 145-154. [CrossRef]

38. McCullagh, P.; Nelder, J.A. Generalized Linear Models; CRC Press: Boca Raton, FL, USA; London, UK; New York, NY, USA; Washington, DC, USA, 1989; Volume 37.

39. Lubke, G.H.; Muthén, B.O. Applying multigroup confirmatory factor models for continuous outcomes to Likert scale data complicates meaningful group comparisons. Struct. Equ. Model. 2004, 11, 514-534. [CrossRef]

40. Norman, G. Likert scales, levels of measurement and the "laws" of statistics. Adv. Health Sci. Educ. 2010, 15, 625-632. [CrossRef] [PubMed]

41. Agarwal, B.L. Basic Statistics; New Age International: New Dheli, India, 2006.

42. Ross, S.M. Introductory Statistics; Academic Press: London, UK, 2005.

43. Brudney, J.L.; England, R.E. Toward a definition of the coproduction concept. Public Adm. Rev. 1983, 43, 59-65. [CrossRef]

44. Galli, F.; Brunori, G.; Di Iacovo, F.; Innocenti, S. Co-producing sustainability: Involving parents and civil society in the governance of school meal services. A case Study from Pisa, Italy. Sustainability 2014, 6 , 1643-1666. [CrossRef] 